[Chem. Pharm. Bull.

36(12)4689-4692(1988) $]$

\title{
Oxidation of Terpenoid Compounds with tert-Butyl Chromate
}

\author{
Angelo C. Pinto, ${ }^{1)}$ Anibal L. Pereira, Alphonse Kelecom, ${ }^{2)}$ \\ Lucia M. Porreca, Nubia M. Ribeiro \\ and RODERICK A. BARNES* \\ Nucleus of Research on Natural Products (NPPN), Federal University \\ of Rio de Janeiro (UFRJ), 21941, RJ, Brazil
}

(Received April 11, 1988)

\begin{abstract}
Oxidation with tert-butyl chromate of a methylene group adjacent to a double bond or aromatic ring has been effected in excellent yield with the majority of a selected group of diterpenes and triterpenes. Some of the factors influencing the course of the reaction are discussed.
\end{abstract}

Keywords oxidation; tert-butyl chromate; diterpene; triterpene; ketone

The biogenetic pathways to a variety of natural products of the terpenoid series involve oxidations at positions adjacent to a double bond. Although apparently easily accomplished in many plant cells, this kind of transformation is often difficult ${ }^{3)}$ in the laboratory. Various reagents such as molecular oxygen, selenium dioxide and chromic acid have been used for effecting oxidations at allylic or benzylic positions of selected molecules, but have not been of general applicability. A recent review on allylic oxidations describes a series of more or less sophisticated reagents, but pays little attention to tert-butyl chromate. ${ }^{4)}$

Our interest in the problem arose from the necessity of preparing 11-keto- $\beta$-amyrin, and although Picard and Spring ${ }^{5)}$ have reported that chromic acid reacted with $\beta$-amyrin benzoate to yield the desired ketone benzoate, we preferred to try tert-butyl chromate which Bloch has used for preparing 7 -ketocholesteryl acetate $(60 \%){ }^{6)}$ The yield of 11 -keto- $\beta$-amyrin acetate was so much better ${ }^{7)}$ than that observed in the chromic acid oxidation that we were encouraged to examine this method of oxidation using various other terpenoid compounds. The results obtained (Table I) make this method the method of choice for oxidations of this kind. Seven of the twelve substrates gave excellent yields $(82-96 \%)$, four proceeded

TABLE I. Oxidation of Terpenoid Compounds with tert-Butyl Chromate

\begin{tabular}{ccccc}
\hline \hline Substrate & Time $(\mathrm{h})$ & Product & Yield $(\%)$ & Ref. \\
\hline $\mathbf{1}$ & 6 & $\mathbf{2}$ & 90 & 7 \\
$\mathbf{3}$ & 6.5 & $\mathbf{4}$ & 84 & 8,9 \\
$\mathbf{5}$ & 7 & $\mathbf{6}$ & 83 & 9 \\
$\mathbf{7}$ & 8 & $\mathbf{8}$ & 65 & 9 \\
$\mathbf{9}$ & 4 & $\mathbf{1 0}$ & 82 & 10 \\
$\mathbf{1 1}$ & $67\left(25^{\circ} \mathrm{C}\right)$ & $\mathbf{1 2}$ & 50 & 11,12 \\
$\mathbf{1 3}$ & 1 & $\mathbf{1 4}$ & 53 & a) \\
$\mathbf{1 5}$ & 6.5 & $\mathbf{1 6}$ & 96 & 13 \\
$\mathbf{1 7}$ & 48 & $\mathbf{1 8}$ & 70 & 15 \\
$\mathbf{2 0}$ & & Mixture & - & - \\
$\mathbf{2 1}$ & 3.5 & $\mathbf{2 2}$ & 80 & 16 \\
$\mathbf{2 3}$ & 1.5 & $\mathbf{2 4}$ & 95 & 17 \\
\hline
\end{tabular}

a) This work; for a similar reaction, see reference 13 . 


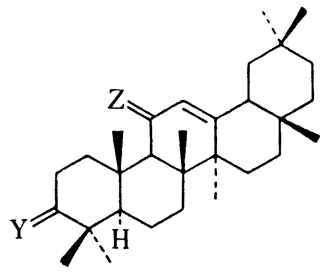

$1: \mathrm{Y}=\beta-\mathrm{OAc}, \alpha-\mathrm{H} ; \mathrm{Z}=\mathrm{H}, \mathrm{H}$ $2: \mathrm{Y}=\beta-\mathrm{OAc}, \alpha-\mathrm{H} ; \mathrm{Z}=\mathrm{O}$ $3: \mathrm{Y}=\beta-\mathrm{OH}, \alpha-\mathrm{H} ; \mathrm{Z}=\mathrm{H}, \mathrm{H}$ $4: \mathrm{Y}=\mathrm{Z}=\mathrm{O}$

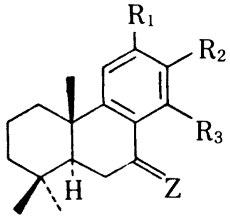

\begin{tabular}{r|llll} 
& $\mathrm{R}_{1}$ & $\mathrm{R}_{2}$ & $\mathrm{R}_{3}$ & $\mathrm{Z}$ \\
\hline $\mathbf{9}$ & $\mathrm{H}$ & $\mathrm{Me}$ & $\mathrm{Et}$ & $\mathrm{H}, \mathrm{H}$ \\
$\mathbf{1 0}$ & $\mathrm{H}$ & $\mathrm{Me}$ & $\mathrm{Et}$ & $\mathrm{O}$ \\
$\mathbf{1 1}$ & $\mathrm{H}$ & iso-Pr & $\mathrm{H}$ & $\mathrm{H}, \mathrm{H}$ \\
$\mathbf{1 2}$ & $\mathrm{H}$ & iso-Pr & $\mathrm{H}$ & $\mathrm{O}$ \\
$\mathbf{1 3}$ & $\mathrm{OAc}$ & iso-Pr & $\mathrm{H}$ & $\mathrm{H}, \mathrm{H}$ \\
14 & OAc & iso-Pr & $\mathrm{H}$ & $\mathrm{O}$
\end{tabular}

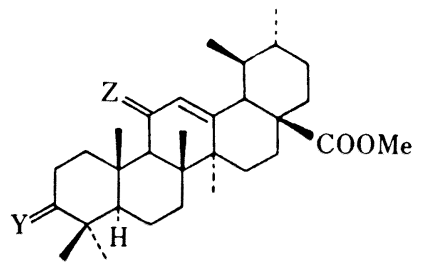

$5: \mathrm{Y}=\beta-\mathrm{OAc}, \alpha-\mathrm{H} ; \mathrm{Z}=\mathrm{H}, \mathrm{H}$

$6: \mathrm{Y}=\beta-\mathrm{OAc}, \alpha-\mathrm{H} ; \mathrm{Z}=\mathrm{O}$

$7: \mathrm{Y}=\beta-\mathrm{OH}, \alpha-\mathrm{H} ; \mathrm{Z}=\mathrm{H}, \mathrm{H}$

$8: \mathrm{Y}=\mathrm{Z}=\mathrm{O}$<smiles>[Z]C1C[C@H]2CCCC[C@]2(C)c2ccccc21</smiles>

$17: Z=H, H$

$18: Z=0$

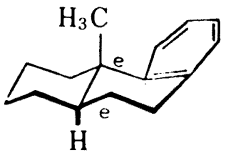

19

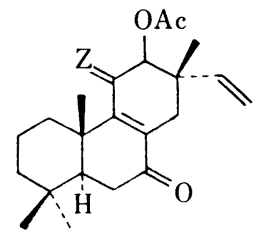

\begin{tabular}{ll|l}
$15: Z=H, H$ & & $R_{1}$ \\
$16: Z=O$ & 20 & Me \\
& 21 & -COOMe \\
& 22 & -COOMe
\end{tabular}<smiles>[R]C[C@]1(C)[C@@H](C)CC[C@]2(C)C([R])=CC(=[Z])C[C@@H]21</smiles>

$\mathrm{R}_{2}$

$2,5-(\mathrm{OMe})_{2} \mathrm{C}_{6} \mathrm{H}_{3}$

$-\mathrm{COOMe}$

COOMe

Chart 1

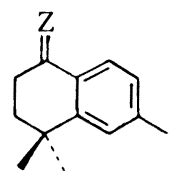

Z

$\mathrm{H}, \mathrm{H}$

$\mathrm{H}, \mathrm{H}$

$23: \mathrm{Z}=\mathrm{H}, \mathrm{H}$

24: $Z=O$

moderately well $(50-70 \%)$ and only one gave an unresolved mixture.

High yields in the oxidations (Table I) of the C-11 methylene in 1 and 15 show that steric hindrance to approach of the oxidant cannot be an important factor, since other evidence ${ }^{18)}$ shows that the 11-position is sterically blocked to a considerable extent by the angular methyl group at carbon 10 .

When two allylic and/or benzylic positions are present, it can be seen, from the result in the oxidation of 9 , that the reagent attacks a ring methylene group in preference to a side chain methylene group. In addition, treatment of 11 shows that a cyclic methylene is oxidized even in preference to an isopropyl group with a hydrogen atom which is benzylic and tertiary. The lower yields in this experiment probably indicate a competition in which the isopropyl group is also undergoing reaction. ${ }^{19)}$ 
The mixture obtained on oxidation of avarol (20) is believed to result from the effect of the ortho methoxyl group in facilitating attack at the adjacent benzylic position (compare with the oxidation of 21). Thus, compound 20 has both a benzylic and allylic methylene group of similar reactivity giving rise to products from attack at both or either of these groups.

The transformation of 6-methoxytetralin to a single ketone, 6-methoxy-1-tetralone, by chromic acid is another example of stabilization of the oxidation intermediate by an ortho or para methoxy group. The increased reaction rate observed in oxidation of abietane $\mathbf{1 3}$ is a further example of the effects of an oxygenated function in the para position.

The contract in the reaction time of $\mathbf{9}$ and $\mathbf{1 7}$ is surprising since in both cases a similar cyclic methylene group is being oxidized. The difference in the two cases is that compound 9 has a trans fusion of rings $\mathrm{A}$ and $\mathrm{B}$ while in $\mathbf{1 7}$ the fusion is cis. If the mechanism of the oxidation involves, as the first step, the loss of a hydrogen atom with either one or two electrons, the intermediate thus obtained should be able to assume a planar configuration for maximum stability. It may be argued that in the trans form ring B can not readily assume a planar structure with both bonds to ring A being equatorial (see structure 19).

The presence in a molecule of other oxidizable groups lowers the yield of the product isolated even when an excess of oxidant is used. Thus in both the pairs of reactions on substrates $1-3$ and $5-7$ the molecule with the free hydroxyl group (i.e. 3 and 7 ) gives lower yields than the corresponding acetate.

The product from treatment of $\mathbf{2 3}$ was rapidly formed in good yield, but if the reaction was allowed to proceed for longer times more polar products were formed as indicated by thin-layer chromatography (TLC). The formation of secondary products was also observed in the oxidations of 11 and 13; maximum yields of the desired ketones were obtained before all the starting material had been consumed. If the reaction was continued until all the substrate had been consumed lower yields (about 30\%) were observed. For maximum yields with substrate 11, the reaction had to be carried out at room temperature instead of at reflux temperature as in the other experiments. The nature of the secondary products in these experiments was not determined. The proton nuclear magnetic resonance $\left({ }^{1} \mathrm{H}-\mathrm{NMR}\right)$ spectrum of the reaction mixture showed that $70 \%$ of the product had a carbonyl group at position 7 (ketone plus diketone), suggesting that there is considerable further attack of the reagent on the initially formed ketone.

The yields were determined by isolation of the product when it was crystalline and by preparation of the 2,4-dinitrophenylhydrazone of the ketone when it was a liquid. The structures of the products were determined by comparison of their properties with those of known sample. The literature references in the last column of Table I indicate the source of information concerning these oxidation products.

\section{Experimental}

Melting points were determined with the Kofler hot-stage and are uncorrected. Infrared (IR) spectra were observed using a Perkin-Elmer 137-B spectrometer. ${ }^{1} \mathrm{H}-\mathrm{NMR}$ spectra $(100 \mathrm{MHz})$ were recorded with a Varian XL100 spectrometer and mass spectra (MS) were observed with a Micro-Mass-12T spectrometer coupled to a Varian MAT-SS-10MS data processor.

tert-Butyl Chromate-Chromic anhydride $(7.4 \mathrm{~g})$ was added in small portions to tert-butanol $(20 \mathrm{ml})$ cooled in an ice-bath. The solution was allowed to warm to room temperature and carbon tetrachloride (52 ml) was added. After separating a small dark layer, the major lower layer was dried over anhydrous sodium sulfate at $5^{\circ} \mathrm{C}$ for $12 \mathrm{~h}$.

Oxidation of Ionene (23), a Typical Procedure-Ionene $(1.7 \mathrm{~g}, 0.01 \mathrm{~mol})$ in $\mathrm{CCl}_{4}(70 \mathrm{ml})$ was added to acetic acid $(23 \mathrm{ml})$, acetic anhydride $(13 \mathrm{ml})$ and tert-butyl chromate solution $(30 \mathrm{ml})$. This mixture was heated to reflux temperature. At intervals an aliquot of the reaction was examined by TLC and after $1.5 \mathrm{~h}$ the ionone had been almost completely consumed.

The reaction mixture was processed by dilution with an equal volume of $5 \%$ oxalic acid, shaking vigorously for several minutes and then separating organic layer. Acids were removed by washing with a $10 \%$ sodium carbonate solution and then the $\mathrm{CCl}_{4}$ was evaporated to leave a residue $(1.8 \mathrm{~g})$ of nearly pure $4,4,6$-trimethyl-3,4-dihydro- $1(2 \mathrm{H})$ - 
naphthalenone (24). An aliquot $(0.2 \mathrm{~g})$ furnished $380 \mathrm{mg}$ of the 2,4-dinitrophenylhydrazone, mp $252-254 \mathrm{C}$, which corresponds to a yield of $95 \%$ of $\mathbf{2 4}$.

Identification of Products-Spectral data were the principal means of identification, although in some cases authentic samples were available for comparison. The more critical evidence for each compound is given.

11-Oxo- $\beta$-amyrenyl Acetate (2): $\mathrm{mp} 259-260^{\circ} \mathrm{C}$. IR (KBr) cm ${ }^{-1}: 1740,1690$. MS $m / z(\%): 482\left(\mathrm{M}^{+}, 4\right), 286(66)$. Further transformations described in reference 7 confirmed the location of the carbonyl group.

3,11-Dioxo- $\beta$-amyrene (4): $\mathrm{mp} 272-273^{\circ} \mathrm{C}$. IR $(\mathrm{KBr}) \mathrm{cm}^{-1}: 1710,1690 .{ }^{1} \mathrm{H}-\mathrm{NMR}\left(100 \mathrm{MHz}, \mathrm{CDCl}_{3}\right) \dot{\delta}: 5.54$ $(1 \mathrm{H}, \mathrm{s})$.

Methyl 11-Oxo-3-acetylursolate (6): IR (KBr) $\mathrm{cm}^{-1}: 1730,1660$. MS $m / z(\%): 526\left(\mathrm{M}^{+}, 30\right) .{ }^{1} \mathrm{H}-\mathrm{NMR}(60 \mathrm{MHz}$, $\left.\mathrm{CDCl}_{3}\right) \delta: 5.66(1 \mathrm{H}, \mathrm{s})$.

Methyl 3,11-Dioxoursolate (8): IR (KBr) $\mathrm{cm}^{-1}: 1745,1705,1650 .{ }^{1} \mathrm{H}-\mathrm{NMR}\left(60 \mathrm{MHz}, \mathrm{CDCl}_{3}\right) \delta: 5.7(1 \mathrm{H}, \mathrm{s})$.

Cleistantha-8,11,13-trien-7-one (10): Ultraviolet (UV) $\lambda_{\max }^{\mathrm{CHCl}_{3}} \mathrm{~nm}(\log \varepsilon$ ): 305 (3.29). IR (KBr): $1675 . \mathrm{MS} \mathrm{m} / \approx$ $(\%): \delta 284\left(\mathrm{M}^{+}, 100\right) .{ }^{1} \mathrm{H}-\mathrm{NMR} \delta: 2.66(2 \mathrm{H}, \mathrm{d})$.

7-Oxoabietatriene (12): IR $(\mathrm{KBr}) \mathrm{cm}^{-1}$ : 1675. MS $m / z(\%): 284\left(\mathrm{M}^{+}, 43\right), 269(\mathrm{M}-15,100) .{ }^{1} \mathrm{H}-\mathrm{NMR}$ $\left(100 \mathrm{MHz}, \mathrm{CDCl}_{3}\right) \delta: 7.84(1 \mathrm{H}, \mathrm{d}, J=2 \mathrm{~Hz}), 7.38(1 \mathrm{H}, \mathrm{dd}, J=8,2 \mathrm{~Hz}), 7.25(1 \mathrm{H}, \mathrm{d}, J=8 \mathrm{~Hz}), 2.73(1 \mathrm{H}, \mathrm{s}), 2.64(1 \mathrm{H}, \mathrm{d}$, $J=4.2 \mathrm{~Hz}$ ).

Sugiol Acetate (14): IR (KBr) $\mathrm{cm}^{-1}: 1754,1672$. UV $\lambda_{\max }^{\mathrm{CH}_{3} \mathrm{OH}}: 290 \mathrm{~nm}$. MS m/z (\%): $342\left(\mathrm{M}^{+}, 12\right) .{ }^{1} \mathrm{H}-\mathrm{NMR}$ $\left(100 \mathrm{MHz}, \mathrm{CDCl}_{3}\right) \delta: 7.96(1 \mathrm{H}, \mathrm{s}), 6.97(1 \mathrm{H}, \mathrm{s}), 2.73(1 \mathrm{H}, \mathrm{s}), 2.64(1 \mathrm{H}, \mathrm{d}, J=4 \mathrm{~Hz})$

12- $\beta$-Acetyl-7,11-dioxo-8(9),15-isopimaradiene (16): IR $(\mathrm{KBr}) \mathrm{cm}^{-1}: 1746,1686,1667$. The structure was established by comparison of the spectral data with the acetylation product obtained from the naturally occurring alcohol, 12-hydroxy-7,11-diketo-8(9),15-isopimaradiene, as described in reference 14.

Methyl $8 \alpha$-2-Oxo-13,14,15,16-tetranorclerod-3-ene-12,19-dioate (22): IR (KBr) cm ${ }^{-1}: 1718,1683 . \mathrm{MS} \mathrm{m} / \mathrm{z}(\%)$ : $322\left(\mathrm{M}^{+}, 10\right) .{ }^{1} \mathrm{H}-\mathrm{NMR}\left(100 \mathrm{MHz}, \mathrm{CDCl}_{3}\right) \delta: 6.20(1 \mathrm{H}, \mathrm{s})$.

cis-9-Oxo-1,2,3,4,4a,9,10,10a-octahydrophenanthrene (18): The 2,4-dinitrophenylhydrazone, mp $183-1844^{\circ}$, was identical (mixture melting point and IR spectrum) with an authentic sample prepared as described in reference 15 .

1-Oxo-4,4,6-trimethyl-1,2,3,4-tetrahydronaphthalene (24): The 2,4-dinitrophenylhydrazone, mp 252-254 C, was identical (mixture melting point and IR spectrum) with an authentic sample prepared as described in reference 17.

Acknowledgements We are grateful to Dr. G. Sodano, Instituto per la Chimica di Molecule di Interesse Biologico, CNR, Italy, for providing us with a generous amount of avarol. This work was supported by grants from the Ministry of Planning (FINEP), the National Research Council (CNPq) and the Research Council of this University (CEPG).

\section{References and Notes}

1) Present address: Institute of Chemistry, Federal University of Rio de Janeiro, 21941 Rio de Janeiro, RJ, Brazil.

2) Present address: Department of General Biology, Federal University Fluminense (UFF), 2400 Niteroi, RJ, Brazil.

3) W. G. Dauben, M. Lorber and D. S. Fullerton, J. Org. Chem., 34, 3587 (1969).

4) J. Muzart, Bull. Soc. Chim. Fr., 1986, 65.

5) C. W. Picard and F. S. Spring, J. Chem. Soc., 1940, 1196.

6) K. Bloch, Helv. Chim. Acta, 36, 1611 (1953); see also K. Hensler and A. Wettstein, ibid., 35, 284 (1952); Y Tsuda, T. Fujimoto and K. Kimpara, Chem. Pharm. Bull., 23, 1290 (1975).

7) R. A. Barnes, A. L. Pereira, T. C. V. Scofield, R. Braz F ${ }^{\circ}$ and A. C. Pinto, Chem. Pharm. Bull., 32, 3674 (1984)

8) I. Kitagawa, K. Kitazawa and I. Iosioka, Tetrahedron, 28, 907 (1972).

9) N. M. Ribeiro, M. S. Thesis, Fed. Univ. of Rio de Janeiro, 1987.

10) A. C. Pinto, M. L. Patitucci, R. S. Silva, P. P. S. Queiroz and A. Kelecom, Tetrahedron, 39, 3351 (1983).

11) R. Zelnik, E. Rabenhorst, A. Haider, J. Lauterwein and W. Wyler, Helv. Chim. Acta, 66, 780 (1983); A. Kelecom, R. Zelnik and E. Rabenhorst, Anais Acad. Brasil. Ciencias, 55, 351 (1983).

12) M. Kitadani, A. Yoshikoshi, Y. Kitahara, J. de P. Campello, J. D. McChesney, D. J. Watts and E. Wenkert, Chem. Pharm. Bull., 18, 402 (1970).

13) T. Matsumoto, S. Usui and T. Morimoto, Bull. Chem. Soc. Jpn., 50, 1575 (1977).

14) A. C. Pinto and C. Borges, Phytochemistry, 22, 2011 (1983).

15) R. A. Barnes and M. T. Beachem, J. Am. Chem. Soc., 77, 5388 (1955).

16) M. C. Frechiani, M. S. Thesis, Fed. Univ. of Rio de Janeiro, 1986.

17) R. A. Barnes and G. R. Buckwalter, J. Am. Chem. Soc., 73, 3858 (1951).

18) Evidence for the reaction of tert-butyl chromate with an isopropyl group is provided by an experiment in which $p$-methylacetophenone was isolated using $\alpha$-terpinene as a substrate; T. Matsuura and T. Suga, J. Org. Chem., 30, 518 (1965).

19) The lack at reactivity of the carbonyl group at position 11 of cortisone and related hormones is atributed to steric hindrance. See J. K. Norymberski and G. F. Woods, J. Chem. Soc., 1955, 3426. 